DOI: $10.17805 /$ zpu.2018.3.9

\title{
Спорт в мире технологий: этос и биополитика
}

\author{
О. В. ПОПОвА
}

ИнСтитУт ФилОсОФИИ РАН

В статье рассмотрено влияние современных технологий на формирование современной биополитики в отношении физической культуры и спорта и дано представление о развитии этоса поведения спортсмена в новых условиях технологической среды.

Констатируется, что ситуацию, которую мы наблюдаем в развитии современного спорта, можно условно назвать экспансией в мир социальных отношений парадигмы большого спорта, носящего в современных условиях развития экономических отношений прежде всего зрелищный характер. Современный спорт, кроме того, неразрывно связан с коммерциализацией современной культуры и распространением общего процесса технологизации всех сфер социальной жизни.

Показано, что следствием развития данных процессов становится превращение человеческого тела в товар (коммодификация телесности) и формирование особой биополитики, которая манипулирует биотехнологическими средствами, улучшающими физические возможности человека, и направлена на производство спортсмена-победителя. Современное общество имеет дело со стратегией действий в режиме цейтнота. Спорт вырабатывает особую форму эффективной темпоральности, в рамках которой получение ре- 
зультатов должно происходить в строго определенный промежуток времени, где каждая секунда способна изменить социальный и онтологический статус спортсмена. В то же время особая зона неопределенности современного спорта связана с пониманием пределов возможностей человека, со своеобразной прочностью его природы, имеющей вполне измеримые параметры, нарушение которых приводит к ее сопротивлению. Физическая выносливость спортсмена, его контроль собственного тела имеют определенные границы, и попытки их преодоления - вызов, который бросает спортсмену общество, тренерский состав и, что немаловажно, он сам. И это фактически означает вызов самой природе, испытание на прочность естественного порядка вещей.

Большой спорт создается в пространстве реализации силы человеческого духа и сопротивления слабой человеческой природы, которую закаляют, улучшают, совершенствуют и которая в каждодневных аскетических практиках модификации демонстрирует границы, прохождение которых ставит человека перед лицом идеального Я, с одной стороны, и перед лицом истощения и смерти - с другой.

Ключевые слова: спорт; биотехнология; философия спорта; биотехнологическое улучшение человека

\section{ВВЕАЕНИЕ}

$\mathrm{C}$ оциальная природа современного спорта связана с его особой институализацией в условиях рыночной экономики и в целом с коммерциализацией современной культуры. Кроме того, в последние десятилетия дух современного спорта определяется общим процессом технологизации всех сфер социальной жизни. Следствием развития данных процессов становится превращение человеческого тела в товар (коммодификация телесности) и формирование особой биополитики, манипулирующей биотехнологическими средствами, улучшающими физические возможности человека, и направленной на «производство спортсмена-победителя». В контексте развития данных тенденций осуществляется процесс коммодификации, капитализации человеческого тела: оно приобретает черты товара, становится частью рыночного обмена, средством заработка, карьерного роста и обретения высокого социального статуса. Все эти черты отражают специфику современного спорта как института, парадигмальное развитие которого фундировано на дискурсах победы и состязательности. Здесь нет места ценности участия как такового, как это было, например, характерно для эпохи Античности, где победа рассматривалась не столько в качестве результата личного вклада спортсмена, сколько считалась признаком особой благосклонности и милости богов (именно поэтому осуждался протест спортсмена против оценки судей: тем самым он шел против воли богов и судей как их представителей).

Современный спортсмен реализует новоевропейский проект отношения к собственному телу. Именно в Новое время инструментальное отношение к человеческому телу приобретает внесакральный характер. Основные черты телесного «канона», выявляемые в эпоху Нового времени, с одной стороны, указывают на тело как отторгаемый, презираемый материальный объект, который обретает свою инструментальную значимость в связи с ответственной целеполагающей деятельностью, с преодолением тела как тела и приданием ему идеальной формы, заданной разумом, с другой - придают ему ценность, рассматривая его как неотъемлемую составляющую человеческого достоинства. Развитие инструментального отношения к своему телу как неотъемлемая характеристика новоевропейского понимания автономии человека являет собой одновременно и акт освоения (и присвоения) субъектом своей телесности, и акт «освоения» тела в различного рода социальных практиках. Особым модусом этого освоения является приписывание телу характеристик деперсонифицированного товара. 
Последовательный либерализм, рассматривающий тело как индивидуальную ценность и отстаивающий право свободного распоряжения им, предоставляет человеку возможность инструментализировать и коммодифицировать его разными способами, придавая ему товарную цену: «В условиях товарного производства, когда человек выступает как товар, обладающий сознанием и самостоятельной деятельностью, как человек-товар, ведущим становится сравнение себя с другим индивидом по частным аспектам, и тем самым самоопределение подменяется определением себя через другого по количественным параметрам» (Пономарчук, Козлова, 2002: 10).

Процесс коммодификации органично вписывается в общекультурный проект конструирования человека и его биотехнологического улучшения. Естественная данность человеческого тела превращается в артефакт, продукт знания и технологий, в вещь, которую можно успешно продать на рынке спорта. Современная наука интенционально превращает человеческую телесность в артефакт, конструирует из естественного - технологическое. В технологической перспективе человеческая природа становится лабильной: ее презентируют, модифицируют, очищают, улучшают в различных вариациях. Всевозможные результаты биотехнологического конструирования требуют создания соответствующей социальной среды, где они могут быть легализованы, «одомашнены».

Целью настоящей статьи является анализ тенденций современной биополитики, направленной на производство спортсмена-победителя благодаря использованию биотехнологических средств, улучшающих физические возможности человека.

\section{СПОРТ И ПРОЧНОСТЬ ЧЕАОВЕЧЕСКОЙ ПРИРОАЫ}

Современное общество имеет дело со стратегией действий в режиме цейтнота. Спорт вырабатывает особую форму эффективной темпоральности, в рамках которой получение результатов должно происходить в строго определенный промежуток времени, где каждая секунда способна изменить социальный и онтологический статус спортсмена. Выжимание спортивных результатов из собственного тела - каждодневная рутинная практика современного спортсмена. Реализация этой практики невозможна без особых характеристик человеческой природы, ее выносливости и прочности. В то же время запас прочности также может иметь вполне измеримые параметры, нарушение которых приводит к ее сопротивлению. Особая зона неопределенности современного спорта связана с пониманием пределов возможностей человека.

Нельзя не вспомнить казус юной российской фигуристки Ю. Антиповой, столкнувшейся с завышенными требованиями своего тренера относительно снижения веса. После чемпионата мира 2014 г. Юля имела вес 30 кг. С признаками анорексии она попала в клинику, лечилась и впоследствии бросила большой спорт. Проблема контроля своего тела (в форме аномальной патологической установки «худеть любой ценой», приводящей к психологическому заболеванию и смертности), которая коснулась Ю. Антиповой, да и многих других спортсменок в фигурном катании, является распространенной практикой для спортсменов в совершенно различных направлениях спорта, а также и в других направлениях современной культуры: кинематографии, танцевальном искусстве.

Современный спорт невозможен без сформированных тысячелетиями эстетических коннотаций. Спорт выражает себя и в зрелищности массовых мероприятий, и в красоте индивидуального тела, раскрывающейся в целесообразных эстетически выверенных движениях, демонстрации отточенных навыков и преодолении собствен- 
ных границ. Эстетика спорта при этом оказывается тесно переплетена с практикой превозмогания боли. К этому добавляются повышенные әстетические требования к человеческому телу. Формируется так называемая эстетика сложности (Боген, 1997), требующая от спортсмена достижения особой выразительности исполнения, в рамках которой предполагается исполнение элементов высшей степени сложности, демонстрация изощренного технического мастерства, недоступного спортсменам прошлого.

Тело спортсмена пропускают через боль бесконечных тренировок, травм и увечий. Его приносят в жертву техникам и технологиям, получая на выходе воплощенное в плоти произведение искусства, олицетворение силы и красоты. Современный спорт получает мощный импульс своего развития путем игнорирования физического дискомфорта и спонтанной реакции на болевые ощущения, демонстрируемой среднестатистическим человеком, и раскрывает культурно обусловленные характеристики эстетического конструирования как женского, так и мужского совершенного тела спортсмена, его внутреннюю интенцию: «Играть в боль, делать боль эстетическим событием» (Аимура, 2014: 60), т. е. неотъемлемой составляющей спорта. Установка на эстетическое улучшение тела сопровождается достаточно жесткими перфекционистскими требованиями, связанными со стремлением произвести впечатление на зрителя, соответствовать внутренним канонам того или иного вида спорта.

Появление казуса фигуристки Ю. Антиповой обусловлено не только техническими проблемами (выполнением әлементов, сложностью партнера при удержаниях), возникающими у фигуристок в случае превышения веса, но и с общей культурной ситуацией, в рамках которой инструментализация собственного тела и контроль за телесностью достигают предела и становятся патологически опасными (Рассказова, 2015: Электронный ресурс).

Проблема контроля своего тела, которая приводит к психологическому заболеванию и смертности, является общей для спортсменов в совершенно различных направлениях спорта. Казус Ю. Антиповой раскрывает глубокий антропологический смысл, связанный с парадоксальным характером взаимодействия человека с собственным телом и природой.

Человеческое существование характеризуется многослойностью, разноаспектностью бытия. В нем как бы происходит взятая в космическом масштабе драма самопреодоления телесного, от тела-вещи - к живому телу, от просто живого тела к человеческому как телу-субъекту, данному в его этической интенциональности. Живые тела отличаются от неживых как утверждающие пространство от только наполняющих пространство, человеческие тела преступают свои собственные пространственные границы, физические возможности, которые ограничивали бы его как вещь, как объект с заданными функциями. Человек хочет быть больше, чем живая вещь. Телесность, человеческая воплощенность выделяется среди других тел мира своей целенаправленной активностью, своей эксцентричностью (Плеснер, 1988). Человек переживает авторство своих действий, он знает себя свободным, и все же, несмотря на эту свободу, он остается прикованным к существованию, которое мешает ему и с чем он должен бороться.

С одной стороны, человек полностью сливается со своим телом, но с другой - он пытается выйти за границы своих телесных функций, чтобы утвердить свое человеческое Я. Человеческое Я оказывается не совпадающим с пространственными границами, протяженностью, заданной телом, с определенными физическими параметрами, оно «простирается» в предельном несогласии со своим собственным существованием 
к другим Я, к поставленным целям и пределам, которые он стремится достичь. Однако его духовное измерение всегда сталкивается с физическим измерением телесности, с ее ограниченностью и наличием пределов ее модификации: «...любое редактирование и улучшение "упрется" в конечном итоге в пределы человеческих возможностей - в "human endurance", т. е. в прочность человека» (Пронин, 2017: 44).

Физическая выносливость спортсмена, его контроль собственного тела имеют определенные границы, и попытки их преодоления - вызов, бросаемый спортсмену обществом, тренерским составом и, что немаловажно, самим собой, фактически означают вызов самой природе, испытание на прочность естественного порядка вещей. Большой спорт создается в пространстве реализации силы человеческого духа и сопротивления слабой человеческой природы, которую закаляют, улучшают, совершенствуют и которая в каждодневных аскетических практиках модификации демонстрирует границы, прохождение которых ставит человека перед лицом Аругого, идеального Я, с одной стороны, и перед лицом истощения и смерти - с другой. Абстрактность идеального (спортсмена, ученика и т. А.) всегда сталкивается с сопротивлением природы, возражением материи, возвращающей высокие замыслы в мир тленного, мир слишком хрупкого, слишком человеческого. В то же время на горизонте появляются так называемые технологии улучшения человека (Human Enhancement technologies), пытающиеся обойти заданный природой запас прочности, достигнуть результатов улучшения физического состояния в наиболее короткий срок и минуя сопротивление природы человека.

\section{СПОРТ И ПРОТЕЗИРОВАНИЕ:}

\section{К СОВРЕМЕННОЙ БИОПОАИТИКЕ ТЕАА}

Парадигма большого спорта осуществляет уверенную экспансию в область социальных отношений. Принцип «быстрее, выше, сильней» давно завоевал прочные позиции в сознании современного индивида и вызвал поиск доступных биотехнологических средств для достижения высоких социальных позиций в различных сферах жизни. Уже сейчас несложно представить себе ряд профессий (например, хирургов, проводящих многочасовые операции), где будет востребовано и, скорее всего, оправдано обществом применение фармакологических средств, улучшающих физические и когнитивные возможности индивида.

Работодатель может сознательно провоцировать такое поведение своего персонала, поскольку для выполнения определенных функций ему требуется не столько личность, сколько идеальный биоробот, полностью справляющийся со своими обязанностями. Современному спортсмену фармакологические компании и развивающиеся генетические технологии также открывают похожие перспективы: возрастающие требования к достижению спортивных результатов при неизменном запасе прочности человеческой природы стимулируют у него поиск усиления собственных физических возможностей. Современный спортсмен поставлен перед необходимостью не только играть за себя, свою команду, страну естественными усилиями, но и включаться в фармакологические, генетические «игры», чтобы сохранить себя как живого индивида в контексте возрастающей состязательности, требующей отдачи до смерти.

На фоне взаимосвязанных тенденций развития практик улучшения в таких сферах жизни, как спорт, сфера труда, образование, возникает проблема определения антропологической нормы в профессиональной деятельности. Вполне возможно, что в кон- 
тексте развития данной тенденции лица дееспособного возраста, не использующие усилители, могут рассматриваться как в некотором роде «инвалиды» в связи с их возможными отклонениями от новых норм профессиональной деятельности. И если, например, в сфере образования распространенной практикой вполне способна стать зависимость от когнитивных усилителей, то в спортивной сфере невидимый, нераспознаваемый допинг или усиленное технологиями тело спортсмена способны породить сверхчеловеческие спортивные результаты.

Предпосылки к этому активно развиваются уже в наши дни. Нацеленность медицины и биотехнологий на усиление станет не менее важной, чем ее нацеленность на восстановление. Протезированный бионический человек становится моделью человека будущего, новой формой мысли о человеке. Однако это не человек-инвалид в традиционном понимании этого слова, это киборг-существо с дополненной технологической реальностью, обеспечивающей ему своеобразное превосходство над обычной человеческой природой. Происходит становление модели человека-с-протезом вне зависимости от того, какого рода и вида будет этот протез: иметь форму внешнего инструмента, усиливающего человеческие физические качества, форму лекарства, резко повышающего когнитивные свойства индивида, форму генетического допинга, повышающего выносливость и спортивные способности.

Классическим примером, вызывающим осмысление дихотомии улучшения и терапии и траекторий развития форм допинга, является случай с паралимпийским спортсменом Оскаром Писториусом, шестикратным чемпионом летних Паралимпийских игр. В связи с ампутацией конечностей Писториусу были прикреплены бионические протезные устройства. Созданные с помощью высоких технологий, они, по мнению ряда критиков, давали ему неоспоримые преимущества перед другими спортсменами, позволяя бегать быстрее, что нарушало дух честной игры спортивных соревнований. В результате Писториус был отстранен от участия в играх с обычными спортсменами. Впоследствии, однако. Спортивный арбитражный суд заявил, что преимущества Писториуса сочетаются с ущербом для его здоровья и неудобствами, возникающими от имеющихся протезов, в том числе связанными с техническими особенностями их использования во время спортивных соревнований, например более медленным стартом. Оправданный Писториус вслед за этим принимал участие не только в Паралимпийских, но и в Олимпийских играх. Его неоднозначная фигура породила множество вопросов, центральным из которых, пожалуй, можно считать вопрос о возможности «честной» игры в эпоху технологий.

Развитие технологий создания бионических протезных устройств, устройств, изначально предназначавшихся для лиц с ограниченной дееспособностью в качестве своеобразной терапии, вызвало прецедент деформации логики олимпийского движения и открыло возможности для наступления эры бионических спортсменов. При этом человечество может столкнуться со следующей тенденцией: чем большее внимание будет уделяться разработке технологических средств лечения и улучшения для спортсменов с ограниченными возможностями здоровья, тем значительней будет увеличение спектра возможностей у спортсменов, не имеющих ограничений по здоровью, спектра, появление которого прежде всего обусловлено действием технологий невидимого конструирования человеческого тела, на которое, очевидно, будут направлены сложные этические алгоритмы выявления различных форм допинга. А. Миа говорит: «...мы не можем предположить, что возникающая эра бионического спортсмена будет хорошо работать для людей с ограниченными возможностями. В то время 
как новые технологии смогут обеспечить модификации, которые превысят возможности так называемых дееспособных спортсменов, последующие нововведения могут быть доступны этим спортсменам, которые могут еще больше расширить границы сравнения. Рассмотрите перспективы более сильных сухожилий, использование лазерной хирургии глаза и даже выборные хирургические вмешательства, направленные на укрепление организма» (Miah, 2008: Электронный ресурс; перевод наш. - О. П.).

В целом әтическая оценка перспектив вторжения в природу человека, связанная с разграничением терапии и улучшения, неизменно упирается в более философские проблемы. По справедливому замечанию Б. Г. Юдина, «когда мы даем тот или иной ответ на вопрос, носит некоторое технологическое воздействие на человека терапевтический характер или же оно направлено на улучшение человека (естественно, улучшение, понятое в евгеническом или, если угодно, трансгуманистическом смысле), мы опираемся при этом на определенное понимание того, “что есть человек"» (Юдин, 2001: 18). Это высказывание применительно к оценке развития технологий в спорте можно перефразировать следующим образом: ответ на вопрос о границах улучшения или терапии всегда будет иметь дело с содержанием, которое мы вкладываем в понятие «спортсмен». Будет ли оно в будущем подразумевать коннотации, связанные с протезированным человеком или генетически усовершенствованным существом, скорее всего, зависит от социально-культурных предпочтений человека будущего и не в меньшей степени от успешности дальнейшего влияния биотехнологий на сферу физической культуры и спорта.

Возможно, будущему человеку как сформированному биотехнологической средой артефакту, т. е. существу, на определенном этапе своего развития преодолевшему свою естественность, апории современного спорта могут показаться непонятными или смешными.

Можно привести еще один пример, связанный с формированием возможностей невидимого генетического конструирования. Обсуждающиеся уже сегодня возможности использования генетических технологий (имеется в виду генная терапия) для увеличения мышечной массы также представляют собой пример трансляции биомедицинских технологий, изначально направленных на лечение заболеваний, в контекст улучшения человека. Изначально подобный вид помощи являлся медикаментозной терапией для таких заболеваний, как мышечная дистрофия, связанная с возрастом саркопения, ВИЧ и СПИА и раковая кахексия. Однако данный вид помощи способен открыть новые неоднозначные в этическом отношении перспективы как для современного бодибилдинга, так и для всего спорта в целом: так, необходимая спортсмену повышенная мышечная масса будет формироваться не посредством длительных и зачастую непосильных тренировок, сопровождающихся усиленным вниманием к нагрузкам для собственного тела, но путем генетических манипуляций, задающих план развития физически выносливого, атлетически сложенного индивида. Тем самым человек будет иметь дело с феноменом невидимого конструирования, сквозь генетическую оптику прорываясь к культивированию «внутренней» красоты и силы. Последние с технологической неизбежностью обретут свой внешний план и станут технологическим фундаментом будущих спортивных результатов.

Развитие технологий улучшения порождает предпосылки для развития кризиса духа спорта с его стремлением в честной игре (fair play). Фактически использование технологий генетического улучшения в спорте связано с социальными эффектами, способными проявиться и в любой другой сфере жизни. Так, в сфере трудовых отно- 
шений возникает возможность новых форм конкуренции людей с усиленными, улучшенными телами. Использование генетического допинга у спортсменов также означает модификацию спорта как сферы занятости, где формат справедливой конкурентоспособности трансформируется в биотехнологические бои.

Экспансия парадигмы большого спорта, проникая в мир социальных отношений, захватывает и ранний период онтогенеза. Так, в случае легализации генетических технологий, направленных на редактирование генома человека, возможно появление практик генетического конструирования детей с целью создания у них новых качеств, позволяющих успешно включаться в конкурентные спортивные отношения, быть в дальнейшем успешным спортивным «человеческим капиталом».

Необходимо подчеркнуть, что мотивы, которые вступают в борьбу за право изменять человеческую природу, в форме ли генетического допинга или редактирования генома человека, как правило, тесно связаны с финансовой составляющей.

\section{ЗАКАЮЧЕНИЕ}

Современный спорт является зоной пересечения самых различных интересов: культуры, бизнеса, политики. В последние десятилетия возникает специфическая инструментализация института физической культуры спорта в контексте бурно развивающейся биотехнологической среды. К пошаговой легитимизации и легализации восприятия спортсмена и его телесности в качестве товаров, которые можно успешно продать на современном рынке труда, добавляется нагрузка в виде складывающегося императива, что тело сможет быть продано более успешно в случае особенной биотехнологической обработки. Спортсмен, становясь объектом коммодификации, будет успешно конкурировать, только приобретая черты биотехнологического артефакта и вступая в состязания с такими же артефактами.

В этой связи особую актуальность приобретает возможность формирования этико-правового дискурса, порождающего своеобразное «возвращение» человеку его отчужденного тела, которое выражается в установлении процедур, призванных обеспечить защиту личностной воплощенности человека

\section{СПИСОК АИТЕРАТУРЫ}

Боген, М. М. (1997) Физическое совершенство как основное понятие теории физической культуры // Теория и практика физической культуры. №5. С. 18-21.

Аимура, И. Н. (2014) Красота и боль: практики присутствия // Вестник Академии русского балета им. А. Я. Вагановой. № 5. С. 53-63.

Плеснер, Х. (1988) Ступени органического и человек / пер. А. Ф. Филиппов // Проблема человека в западной философии: переводы / сост. и послесл. П. С. Гуревича ; общ. ред. Ю. Н. Попова. М. : Прогресс. 552 с. С. 96-151.

Пономарчук, В. А. Козлова, В. С. (2002) Институт спорта (история и реалии). Минск : БГАФК. 266 с.

Пронин, М. А. (2017) Редактирование солдата: к постановке проблемы // Психология служения. Материалы межрегиональной научно-практической конференции психологов силовых структур / под ред. Караяни А. Г. и др. М. : Военный университет. С. 33-58.

Рассказова, И. (2015) Фигуристка Юлия Антипова: Я не самоубийца, чтобы вернуться к этому партнеру... [Электронный ресурс] // Комсомольская правда. 16 февраля. URL: https:// www.kp.ru/daily/26342.5/3225455/ (дата обращения: 12.12.2017).

Юдин, Б. Г. (2001) Человек как объект технологических воздействий // Человек. №3. C. 5-20. 
Miah, A. (2008) Paralympics 2.0 [Электронный ресурс] // The Hastings Center. 6 июня. URL: https://www.thehastingscenter.org/paralympics-2-0/ (дата обращения: 24.10.2017).

Аата поступления: 12.04 .2018 г.

\section{SPORT IN THE WORLD OF TECHNOLOGY: \\ ETHOS AND BIOPOLITICS \\ O. V. POPOVA \\ RAS INSTITUTE OF PHILOSOPHY}

The article considers the influence of modern technologies on the formation of modern biopolitics in relation to physical culture and sport. It gives an insight into the development of ethos of the athlete's behavior under the new conditions of the technological environment.

It is argued that the situation that we can see in the development of modern sport can be conditionally called an expansion in the world of social relations of the big sport paradigm. It implies that, under the modern conditions of the development of economic relations, sport has an entertaining nature in the first place. Besides, modern sport is inextricably linked with the modern culture becoming commercialised and the general process of technological development spreading to all spheres of social life.

It is demonstrated that the development of these processes results in the transformation of the human body into a commodity (the commodification of corporality) and the formation of a special biopolicy that manipulates biotechnological means improving human physical capabilities and is aimed at producing the winner sportsman. Modern society deals with the strategy of actions in the time-trouble mode. Sport develops a special form of effective temporality, where results must bust be achieved in a strictly defined time interval, where every second is capable of changing the social and ontological status of the athlete. At the same time, a special zone of uncertainty in modern sport is connected with the understanding of the limits to human capabilities, with the unique strength of its nature, which has completely measurable parameters, the violation of which leads to its resistance. An athlete's physical endurance, control of their body have definite limits, and any attempts to overcome them pose a challenge to the athlete by the society, coaching staff, and, most importantly, by themself. It actually means a challenge to nature itself, a test for the strength of the natural order of things.

High performance sport is created in the space of application of human spiritual strength and the resistance of weak human nature, which is tempered, enhanced, and perfected; additionally, in everyday ascetic practices of modification, human nature demonstrates the boundaries that, if crossed by human, put them face to face with the ideal self, on the one hand, and with exhaustion and death, on the other hand.

Keywords: sport; biotechnology; philosophy of sport; biotechnological human enhancement

\section{REFERECES}

Bogen, M. M. (1997) Fizicheskoe sovershenstvo kak osnovnoe poniatie teorii fizicheskoi kul'tury. Teoriia i praktika fizicheskoi kul'tury, no. 5, pp. 18-21. (In Russ.).

Dimura, I. N. (2014) Krasota i bol': praktiki prisutstviia. Vestnik Akademii russkogo baleta im. A. Ia. Vaganovoi, no. 5, pp. 53-63. (In Russ.).

Plesner, Kh. (1988) Stupeni organicheskogo i chelovek / transl. by A. F. Filippov. In: Problema cheloveka $v$ zapadnoi filosofii: perevody / comp. by P. S. Gurevicha ; ed. by Iu. N. Popov. Moscow, Progress. 552 p. Pp. 96-151. (In Russ.).

Ponomarchuk, V. A. and Kozlova, V. S. (2002) Institut sporta (istoriia i realii). Minsk, BGAFK. 266 p. (In Russ.).

Pronin, M. A. (2017) Redaktirovanie soldata: k postanovke problem. In: Psikbologiia sluzheniia. Materialy mezhregional' noi nauchno-prakticheskoi konferentsii psikbologov silovykh struktur / ed. by Karaiani A. G. et al Moscow, Voennyi universitet. Pp. 33-58. (In Russ.). 
Rasskazova, I. (2015) Figuristka Iuliia Antipova: Ia ne samoubiitsa, chtoby vernut'sia k etomu partneru... Komsomol'skaia Pravda, 16 February [online] Available at: https://www.kp.ru/ daily/26342.5/3225455/ (access date: 12.12.2017). (In Russ.).

Iudin, B. G. (2001) Chelovek kak ob»ekt tekhnologicheskikh vozdeistvii. Chelovek, no. 3, pp. 5-20. (In Russ.).

Miah, A. (2008) Paralympics 2.0. The Hastings Center, 6 June [online] Available at: https:// www.thehastingscenter.org/paralympics-2-0/ (access date: 24.10.2017). (In Russ.).

Submission date: 12.04 .2018 .

Попова Ольга Владимировна - кандидат философских наук, ведущий научный сотрудник, руководитель сектора гуманитарных экспертиз и биоэтики Института философии РАН. Адрес: 109240, г. Москва, ул. Гончарная, д. 12, стр. 1. Эл. адрес: J-9101980@yandex.ru

Popova Olga Vladimirovna, Candidate of Philosophy, Leading Research Fellow, Head, Sector of Humanitarian Expertise and Bioethics, RAS Institute of Philosophy. Postal address: 12, Bldg. 1, Goncharnaya St., Moscow, Russian Federation, 109240. Tel.: +7 (903) 515-76-41. E-mail: J-9101980@ yandex.ru 